\title{
A HEXAGONAL MULTIPOINT PH AND TEMPERATURE SENSING NEEDLE FOR 3D PIG HEART MUSCLE PH MONITORING WITH TEMPERATURE COMPENSATION
}

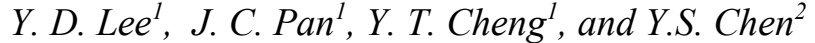 \\ ${ }^{1}$ Microsystems Integration Laboratory, Department of Electronics Engineering, \\ National Chiao Tung University, HsinChu, Taiwan \\ ${ }^{2}$ Department of Cardiovascular Surgery, National Taiwan University Hospital, Taipei, Taiwan
}

\begin{abstract}
The paper presents a hexagonal silicon microneedle with an outer diameter of $0.7 \mathrm{~mm}$ same size as the medical needle of $22 \mathrm{G}$, where an $\mathrm{Au} / \mathrm{Cu}$-based resistive temperature probe is back-to-back, flip-chip boned with a ( $\mathrm{IrOx}) / \mathrm{AgCl}$-based $\mathrm{pH}$ probe using $\mathrm{SU}-8$ as the bonding layer. The microneedle containing two sets of temperature and $\mathrm{pH}$ sensors can exhibit a linear sensitivity of $0.0298 \Omega /{ }^{\circ} \mathrm{C}$ and $-58 \mathrm{mV} / \mathrm{pH}$ respectively and sustain up to $\sim 3.8 \mathrm{Nt}$ compressive load before buckling failure that is mechanically robust enough to penetrate myocardium. Owing to the reduction of process complexity by separating probe fabrications, the new needle can have at least $10 \%$ overall improvement in comparison with the prior arts in terms of the probe size and sensitivity and $220 \%$ improvement in terms of buckling strength. In addition, a $3 \mathrm{D} \mathrm{pH}$ measurement of a pig heart has been performed with temperature compensation in this work.
\end{abstract}

\section{INTRODUCTION}

Small form factor is the key feature in the next generation biomedical instruments which facilitate the new exploratory in the signal detection down to the tissue or even cell level [1-3]. For instance, Ivorra et al. developed a minimally invasive needle shaped probe to measure the electrical impedance of living tissues of rat kidneys for the study of the extracellular medium and found the appearance of $65 \%$ impedance change while the kidney was kept in an ischemia period of 45 minutes [1]. Chan et al. demonstrated a polycrystalline diamond neural probe equipped with both electrical and electrochemical recording abilities can efficiently detect Norepinephrine in vitro [2]. Zheng et al. employed a silicon -nanowire field-effect transistor array for multiplexed real-time monitoring of protein markers and telomerase activity with high sensitivity and selectivity activity in clinical samples, which disclosed the potential application of the platform for diagnosis and treatment of cancer and other complex diseases [3].

On the other hand, recent researches in 3-D measurement has paved a way to help us understand the biosignal distribution and thus the development of appropriate therapies in a biological system. Nanoscale devices, such as nanowire or nanotube FET probes, 3-D macroporous nanoelectronic scaffolds etc. have been successfully developed for intracellular electrical recording of action potentials from single live cells to tissues as well as 3-D neural activity mapping for the fundamental biophysical studies and medical monitoring and intervention [4]. The establishment of multicellular $3 \mathrm{D}$ aggregation in vitro model based on the recorded electrical potential and impedance using the combination of the bio-hybrid sensors like integrated electrode arrays with a self-assembling peptide nanofiber scaffold for mimicking the cellular microenvironment in a living organism has become a critical research task for determining the effectiveness of drugs and therapies $[5,6]$.

Prior studies have shown the heart sarcolemma failure can be detected via the change of the $\mathrm{pH}$ value of heart muscle, resulting from the massive influx of calcium into the muscle cells during hypoxia [7]. Cardiovascular surgeon could have a lower surgery risk as long as there is a minimally invasive probe can be inserted in the right or left ventricular anterior wall for fixed-point temperature and $\mathrm{pH}$ sensing. Previously, we successfully developed a silicon probe integrated with multiple $\mathrm{Au} / \mathrm{Cu}$-based resistance temperature detectors (RTDs) and three (IrOx)/AgCl-based $\mathrm{pH}$ meters for heart muscle monitoring $[8,9]$. The integrated sensing probe could detect the $\mathrm{pH}$ variance at different sites to show the real-time status of muscle like decomposition and related germs breeding and $\sim 3^{\circ} \mathrm{C}$ difference between the outer and inner parts of the pig heart, which is an important factor in heart surgery.

Nevertheless, bulky needle size and handling difficulty resulting from tens of interconnects and asymmetrical needle shape, respectively, still prevent the probe from the translation of clinical advances into practice. This paper will demonstrate a new probe design with simpler fabrication processes by bonding two micromachined trapezoidal probes to form a robust hexagon-shaped needle where the space for sensor feedthroughs and process-sensitive materials can be effectively reduced and protected for better sensing performance.

\section{PROBE DESIGN AND FABRICATION}

In the prior probe design, a total of six sensors, three for each temperature and $\mathrm{pH}$ sensor respectively, are distributed in a silicon shank expected to detect the signals at three different depth of myocardium as a result of a $1.1 \mathrm{~mm}$ wide probe where sixteen electrical interconnects are distributed. For realizing minimal wound that can recover without being sutured and having a good surgical field that requires the probe to be placed in the back site of heart limited by chest cavity during open cheat surgery, it is necessary to resize the probe. Fig. 1 shows the new cardiac sensing probe whose shank width and length have been reduced from 1.1 to $0.7 \mathrm{~mm}$ and 8 to $6 \mathrm{~mm}$, respectively, in comparison with that of the prior one. The newest needle comprises of two silicon probes back-to-back flip-bonded to form a hexagonal type needle where $\mathrm{pH}$ and thermal sensors are placed at two sides of the probe shank, respectively, which can also effect resolve the indispensable space resulting from the interconnects.

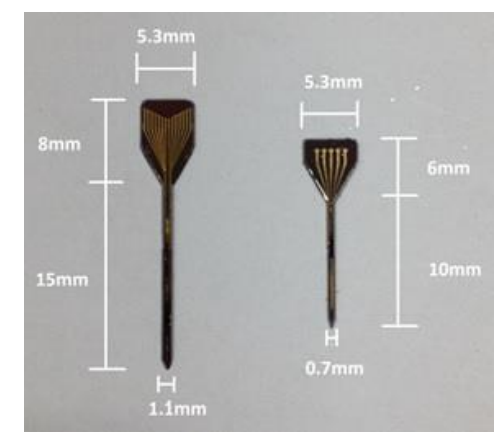

Fig. 1. A micrograph of two different cardiac sensing probes: prior design (left [9]) and the new design (right). 


\section{Temperature and pH Sensors}

The temperature sensor is designed with a serpentine-shaped resistance temperature detector (RTD) made of electroplated $\mathrm{Cu}$ with $\mathrm{Au}$ same as the prior work because of high temperature coefficient, TCR $4.29 \times 10^{-3} /{ }^{\circ} \mathrm{C}$, good linear dependence of resistivity from -100 to $260^{\circ} \mathrm{C}$, and compatible with CMOS backend process. Besides, Au surface on the electrical interconnects can exhibit good biocompatibility and be easily applied with any flexible electrical feedthrough via solder bonding or metal-metal thermal-compressive bonding for in-situ monitoring heart muscle. In the temperature sensing probe, there are only two sensing sensors spaced with $5 \mathrm{~mm}$ apart for myocardium temperature monitoring at different depth. As for the $\mathrm{pH}$ probe, $600 \mathrm{~mm}$ x 200mm silver-silver chloride $(\mathrm{Ag} / \mathrm{AgCl})$ and Iridium oxide $\left(\mathrm{IrO}_{\mathrm{x}}\right)$ pads are used for $\mathrm{pH}$ reference and sensing electrode, respectively. Nernstian equation listed as follows show the $\mathrm{pH}$ sensitivity will be $-59 \mathrm{mV} / \mathrm{pH}$ at $25^{\circ} \mathrm{C}$ if the sensing film electrodes are with space charges:

$$
E=E^{0}-2.303 \frac{R T}{F} \mathrm{pH}=E^{0}-0.05916 \mathrm{pH}
$$

where $F$ is Faraday's constant with a value about $96500 \mathrm{C} / \mathrm{mole}, R$ is the value of gas constant $8.314 \mathrm{~J} / \mathrm{mole} \mathrm{K}$, and $E^{0}$ is the standard potential with a value of $577 \mathrm{mV}$ for $\mathrm{AgCl}$. The $\mathrm{pH}$ value is measured by open circuit method.

\section{Microneedle Fabrication}

Fig. 2 shows the process flow for the cardiac sensing microneedle fabrication using two $250 \mu \mathrm{m}$ thick $\mathrm{Si}(100)$ substrates, one for temperature probe and the other for $\mathrm{pH}$ probe. Firstly, thermal oxide $(6000 \AA)$ and LPCVD nitride layer $(7000 \AA)$ are deposited and photo-patterned using PR AZ4620 and reactive ion etcher on the silicon substrates as electrical insulation and mask layer for $\mathrm{KOH}$ silicon anisotropic etching (Fig. 1(a)). Secondly, sputtering and photo -patterning a layer of $\mathrm{Ti} / \mathrm{Cu} / 50 \mathrm{~nm} / 100 \mathrm{~nm}$ on the front side of the substrate as a seed layer for electroplating $1 \mu \mathrm{m}$ thick $\mathrm{Cu}$ patterned as sensor parts and covered with electroless-plated $\mathrm{Ni}(0.1 \mu \mathrm{m}) / \mathrm{Au}(0.4 \mu \mathrm{m})$ (Fig. 1(b) or Fig. 1(d)). The Au layer can be used for the prevention of copper oxidation. So far, both temperature and $\mathrm{pH}$ probes have been proceeded in common. The temperature probe will be realized after the seed layer removal by $\mathrm{Cu}$ etchant and buffer $\mathrm{HF}$ solution and then $\mathrm{KOH}$ etching (Fig. 1(c)).

For the $\mathrm{pH}$ probe fabrication, the aforementioned substrate is selectively electroplated with $1.5 \mu \mathrm{m}$ thick Ag pads, which will be chlorinated with $50 \mathrm{mM} \mathrm{FeCl}_{3}$ solution for 20 second and soaked in a $3 \mathrm{M} \mathrm{KCL}$ solution to stabilize the potential of $\mathrm{AgCl}$ for the realization of the on-probe $\mathrm{Ag} / \mathrm{AgCl}$ reference electrode fabrication (Fig. 2(e)) . The substrate is then covered with a layer of $\mathrm{Cu}$ to protect the as-fabricated interconnects and pads for probe patterning by $\mathrm{KOH}$ etching (Fig. 2(f)). After the removal of the $\mathrm{Cu}$ layer, the $\mathrm{IrO}_{\mathrm{x}}$-based working electrode is fabricated on the top of the $\mathrm{Cu} / \mathrm{Ni} / \mathrm{Au}$ pads area using the cyclic voltammetry electroplating method where the electroplating solution contains $0.75 \mathrm{mg}$ of $\mathrm{IrCl}_{4}$ dissolved in a solution of $50 \mathrm{~mL}$ of D. I. water, $0.5 \mathrm{~mL} 30 \% \mathrm{H}_{2} \mathrm{O}_{2}$, and $250 \mathrm{mg} \mathrm{Na} \mathrm{C}_{2} \mathrm{O}_{4}$ and will be adjusted to have a $\mathrm{pH}$ value of 10.5 by adding $1 \mathrm{M} \quad \mathrm{K}_{2} \mathrm{CO}_{3}$ and stabilized for 2 days. The electrochemical method is conducted using a three electrode cell system, commercial $\mathrm{Ag} / \mathrm{AgCl}$ as a reference electrode, platinum foil as a counter electrode, and $\mathrm{Au}$ pad of the $\mathrm{pH}$ probe as a working electrode. Adapt cyclic voltammetry method from $0 \mathrm{~V}$ to $0.6 \mathrm{~V}$ with respect to the $\mathrm{AgCl}$ electrode at the rate $20 \mathrm{mV} / \mathrm{s}$ for 280 cycles to electroplate the $\mathrm{IrO}_{\mathrm{x}}$ film followed by bathing the substrate in a $\mathrm{pH} 7$ buffer solution for $15 \mathrm{hrs}$. for potential stabilization of the $\mathrm{IrO}_{\mathrm{x}}$.

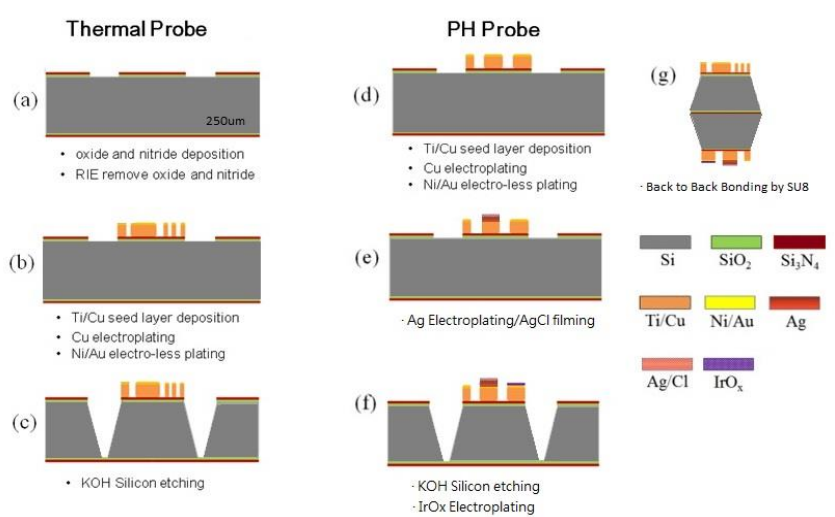

Fig. 2. Process flow for the cardiac sensing probe fabrication.

Once two sensor probes are fabricated separately, the probes will be back-to-back flip-chip bonded using SU- 8 at $150^{\circ} \mathrm{C}$ for $3 \mathrm{~min}$. to form the hexagonal multipoint $\mathrm{pH}$ and temperature sensing needle.

\section{RESULTS AND DISCUSSION}

Figure 3 shows the as-fabricated hexagonal microneedle comprising of two sets of RTDs and pH meters (Fig. 1(a) and (b)). Figure 1(c) and (d) show close views on the shank and tip, the RTD, and the $\mathrm{pH}$ meter of the microneedle. Fig. 4 shows the characterization results from one pair of the RTDs and $\mathrm{pH}$ meters on the hexagonal microneedle whose sensitivities are $0.0298 \Omega /{ }^{\circ} \mathrm{C}$ and $-58 \mathrm{mV} / \mathrm{pH}$ i.e. $\sim 10 \%$ performance improvement than the prior art mainly due to process simplicity. Besides, excellent linear dependence of the resistivity on temperature and the open circuit potential (OCP) and $\mathrm{pH}$ values respectively have been accomplished with higher than $99 \%$ correlation. The measured titration cycle (Fig. 4(b)) shows the $\mathrm{pH}$ sensor can exhibit excellent reversibility.

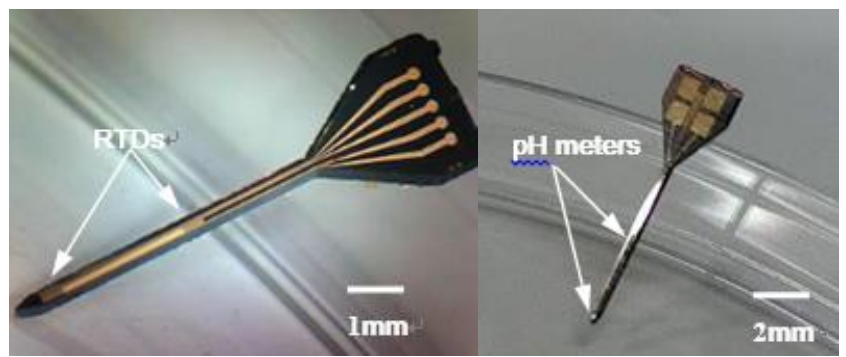

(a)

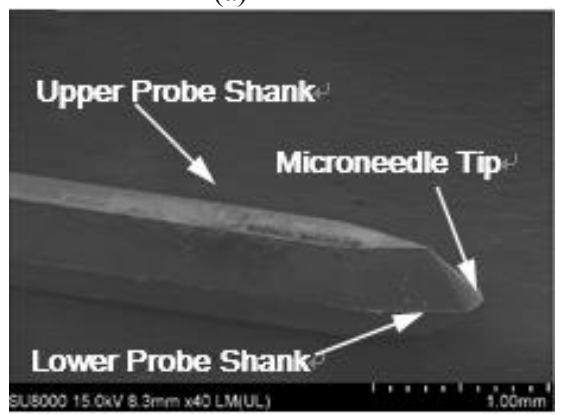

(c) (b)

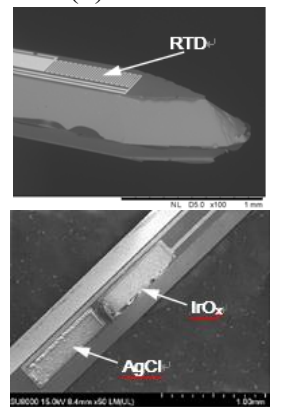

(d)
Fig. 3. As-fabricated hexagon shaped multipoint $p H$ and temperature sensing probe, (a) RTD side, (b) pH meter sides, (c) probe tip and shank, (d) enlarged view on the resistive temperature sensor (top) and enlarged view on the pH meter (down). 


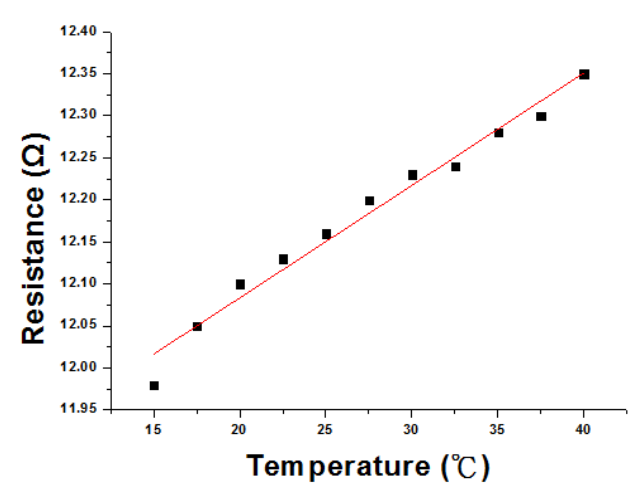

(a)

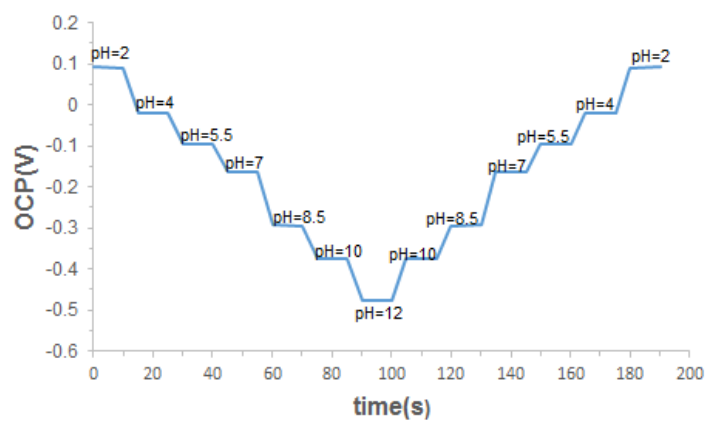

(b)

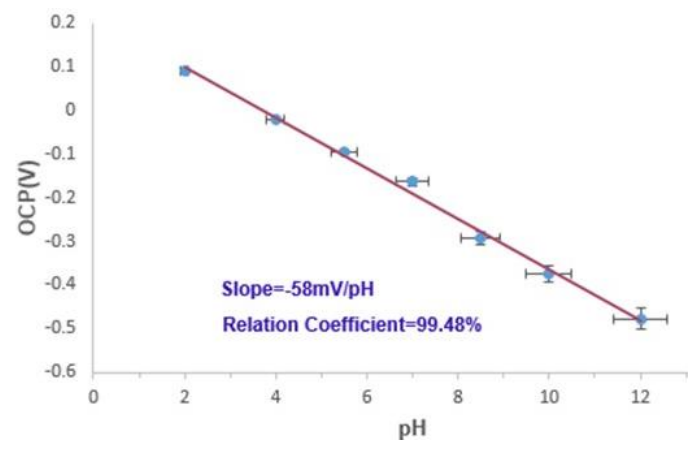

(c)

Fig. 4. (a) Resistance vs. temperature from one of RTDs, TCR of the $\mathrm{Cu} / \mathrm{Ni} / \mathrm{Au} \quad(1 \mu \mathrm{m} / 0.1 \mu \mathrm{m} / 0.4 \mu \mathrm{m}) \sim 4.79 \times 10^{-3} /{ }^{\circ} \mathrm{C}$ with linearity of 99.1\%. (b) The measured titration cycle, and (c)The OCPs from one of $\mathrm{pH}$ meters measured by dipping the probe in $\mathrm{pH} 2,4,6,7,8$ and 10 buffer solutions, the meter sensitivity is $-58 \mathrm{mV} / \mathrm{pH}$ with linearity of $99.5 \%$.

Fig. 5 shows the measured maximum compressive strength of the microneedle, i.e. before buckling failure, about $2.2 \mathrm{X}$ improvement, i.e. from 1.7 to $3.8 \mathrm{Nt}$, in comparison with that of a single trapezoidal probe. Because the needle is broken as two parts and the failure interface does not happen in the SU- 8 bonding layer, the maximum load to cause the probe to be in a state of unstable equilibrium, i.e. failure, can be estimated by the equation as follows:

$$
F=\frac{\pi^{2} E I}{(K L)^{2}}
$$

where $F$ : maximum load, $E$ : modulus of elasticity, $I=$ area moment of inertia of the cross section of the probe, $L=$ unsupported length of column, and $K$ : column effective length factor. Since the maximum load is proportional to the area moment of inertia of the cross section, the $2.2 \mathrm{X}$ improvement is lower than the theoretical calculation. It could be attributed to uneven load applied on the probe during the test. Further investigation is required to understand the failure mechanism.

Fig. 6 shows the multipoint temperature measurement in the pig heart kept at $5^{\circ} \mathrm{C}$ in a refrigerator for 2 hours and then tested @ $24^{\circ} \mathrm{C}$. With a good temperature match between the RTDs and the commercial sensors, $\sim 3^{\circ} \mathrm{C}$ difference detected at two points, 0.5 and $1 \mathrm{~cm}$ underneath the pig heart surface respectively, indicates that temperature compensation is required for the $\mathrm{pH}$ detection in thick muscle. In addition, according to Nernstian relation (Eq. (1)), the $\mathrm{pH}$ value is correlated with environmental temperature. Fig. 7 shows the OPV measurement under different temperature where the $\mathrm{pH}$ values are calibrated using a commercial $\mathrm{pH}$ probe. The slope of the regression lines increases with increasing temperature. Thus, temperature compensation is required for following $\mathrm{pH}$ monitoring of pig heart muscle owing to the temperature difference within the pig muscle. Fig. 8 shows a real-time 3D pH measurement in a pig heart. A pH profile at four different positions (A, B, C and D) with different time, $t=0,2$, and 4 hours shows that the $\mathrm{pH}$ variance and difference at the same depth and in the inner and outer sides of the heart will become smaller after with temperature compensation. The 3D profile also shows the status of heart muscle will be similar at the positions with the same depth and could be different with muscle depth. Meanwhile, it is found that the detected $\mathrm{pH}$ values are larger at the positions close to the heart surface, which is consistent with the prior result. The higher $\mathrm{pH}$ value can be attributed to the decomposition of glycogen accompanied by the generation of amino acid and peptide at a higher temperature.

The hexagonal microneedle can be also accomplished using double-side $\mathrm{KOH}$ silicon etching instead of back-to-back flip-chip bonding process. Double side etching process can make the sensing needle with better structure rigidity due to the lack of bonding interface in between two probes. However, process compatibility and manufacture yield should be taken into consideration. A passivation layer is required to protect the working and sensing electrodes of the $\mathrm{pH}$ probe in the $\mathrm{KOH}$ etching and can be patterned without causing any detrimental effects on the IrOx electrode after the $\mathrm{KOH}$ etching.

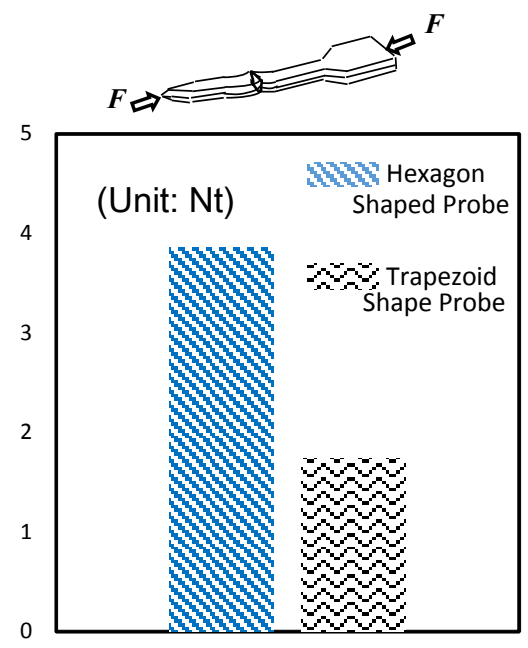

Fig. 5. Maximum compressive strength characterization (Inset). There are total 12 samples tested (6 for each case). 


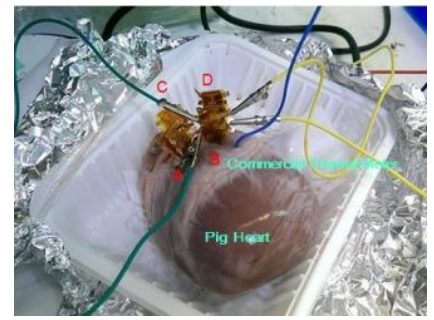

(a)

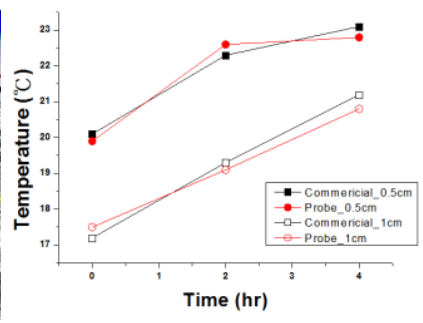

(b)
Fig. 6. A multipoint temperature measurement in a pig heart using commercial temperature sensors and the as-fabricated needles: (a) the measurement setup and (b) the temperature difference of $\sim 3^{\circ} \mathrm{C}$ detected at two points, which are located $0.5 \mathrm{~cm}$ and $1 \mathrm{~cm}$. respectively, underneath the pig heart surface.

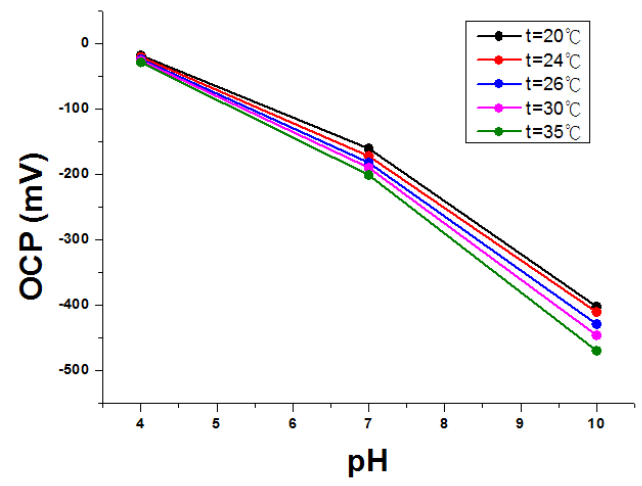

Fig. 7. The OPV measurement under different temperature.

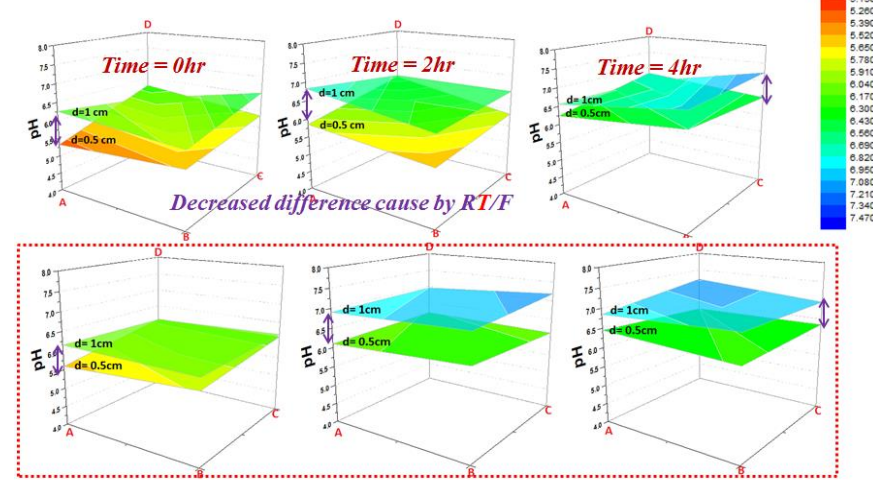

Fig. 8. Multipoint $p H$ measurement in a pig heart: the $p H$ profile at four different positions $(A, B, C$ and $D)$ : the upper/lower parts are without/with temperature compensation, respectively.

\section{CONCLUSION}

In conclusion, we have successfully demonstrated a hexagonal silicon microneedle with the size of $22 \mathrm{G}$. The microneedle comprises of two sets of temperature and $\mathrm{pH}$ sensors which can provide the functionality of multipoint sensing and sustain up to $\sim 3.8 \mathrm{Nt}$ compressive load before buckling failure that is mechanically robust enough to penetrate myocardium. Owing to the reduction of process complexity by separating probe fabrications, the new microneedle can exhibit better electrical and mechanical characteristics in comparison with the prior work. In addition, a 3D pH measurement of a pig heart has been performed with temperature compensation, which shows smaller $\mathrm{pH}$ variance and difference at the same depth and in the inner and outer sides of the heart. We think the microneedle can facilitate correct multi-point $\mathrm{pH}$ detection potential for enhancing the successful rate of heart transplant surgery.

\section{ACKNOWLEDGEMENT}

This work was supported by MOST 104-2220-E-009-001 and 104-2218-E-009-030 projects and in part by the ATU Program funded by MOE in Taiwan. The authors would like to thank Winbond-NCTU diamond laboratory for the travel support and the Nano Facility Center in NCTU for the support of fabrication facility.

\section{REFERENCES}

[1] A Ivorra, R Gómez, N Noguera, R Villa, A Sola, L Palacios, G Hotter, and J Aguiló. "Minimally Invasive Silicon Probe for Electrical Impedance Measurements in Small Animals." Biosensors and Bioelectronics, 19, pp.391-399, (2003).

[2] H. Y. Chan, M. Varney, S. Hatch, and D. M. Aslam, "Implantable Polycrystalline Diamond Neural Probe for in Vivo and in Vitro Physiological Recording.", IEEE Transducers 09, Denver, June, pp.1202-1205, (2009).

[3] G. Zheng, F. Patolsky, Y. Cui, W. U. Wang, and C. M. Lieber, "Multiplexed Electrical Detection of Cancer Markers with Nanowire Sensor Arrays.”, Nat. Biotech., 23, pp. 1294 - 1301 (2005).

[4] X. Duan and Charles M. Lieber, "Nanoelectronics Meets Biology: From New Nanoscale Devices for Live-Cell Recording to 3D Innervated Tissues.", Chem. Asian J., 8, pp. $2304-2314,(2013)$.

[5] A. Reininger-Mack, H. Thielecke, and A. A. Robitzki, "3D-biohybrid Systems: Applications in Drug Screening.", Tren. in Biotech., 20, pp. 56-61, (2002).

[6] S. Zhang, "Designer Self- Assembling Peptide Nanofiber Scaffolds for Study of 3-D Cell Biology and Beyond.." , Adv. in Can. Res., 99, pp. 335-362, (2008).

[7] C. E. Holland, and R.E. Olson, "Prevention by Hypothermia of Paradoxical Calcium Necrosis in Cardiac Muscle", Journal of Molecular and Cellular Cardiology, 7, pp. 917-918, (2006).

[8] K. S. Li, T. Y. Chao, Y. T. Cheng, J. -K. Chen and Y. -S. Chen, "Temperature Sensing Probe Integrated with an SU-8 Flexible Ribbon Cable for Heart Surgery Application", IEEE Transducers 2011, Beijing, June, pp. 2180-2183, (2011).

[9] Y. T. Fan, Y. C. Chen, Y. T. Cheng and Y. S. Chen, "Design and Fabrication of a Multipoint $\mathrm{pH}$ and Temperature Recording Probe for Real-Ttime Heart Muscle Monitoring", IEEE Transducers 13, Barcelona, June, pp. 1263-1266, (2013).

\section{CONTACT}

*Y. T. Cheng, tel: +886-3-5712121, ext. 54169; ytcheng@g2.nctu.edu.tw 